\title{
LÒNG TRUNG THÀNH KHÁCH HÀNG ĐỐI VỚI HÀNG NỘI ĐỊA TRÊN THI TRƯỜNG ĐIỆN TỦ TRONG ĐẠI DỊCH COVID-19
}

\author{
BÙI THÀNH KHOA, VÕ THI THẢO UYÊN, NGUYẼ̃N THI TRANG OANH, ĐẶNG \\ CỦU HANH DUNG \\ Khoa Thuơng mại Du lịch, Trường Đại học Công nghiệp thành phố Hồ Chí Minh \\ buithanhkhoa@iuh.edu.vn
}

Tóm tắt: Sự bùng nổ của đại dịch Covid-19 đã làm cho khách hàng lo lắng về sự lây lan của bệnh dịch khi mua hàng hóa từ các cửa hàng trực tuyến quốc tế, đồng thời việc vận chuyển hàng hóa giữa các quốc gia trở nên khó khăn hơn. Do đó, khách hàng đang có xu hướng chuyển sang lựa chọn các hàng hóa nội địa cho việc mua sắm trực tuyến từ các thị trường điện tử. Nghiên cứu này nhằm đánh giá các tác động của niềm tin, tính vị chủng, chất lượng dịch vụ, rủi ro cảm nhận đến lòng trung thành của khách hàng đối với các hàng hóa nội địa khi mua sắm trực tuyến trên các sàn giao dịch điện tử. Nghiên cứu sử dụng phương pháp hỗn hợp để đạt được các mục tiêu nghiên cứu. Kết quả cho thấy niềm tin, tính vị chủng và chất lượng dịch vụ tác động tích cực đến lòng trung thành của khách hàng. Trong khi đó, rủi ro cảm nhận có ảnh hưởng tiêu cực đến lòng trung thành của khách hàng đối với các sản phẩm nội địa trên thị trường điện tử trong thời điểm đại dịch Covid-19. Một số hàm ý quản trị cũng được đề xuất dựa trên kết quả nghiên cứu để gia tăng lòng trung thành của khách hàng đối với các hàng hóa nội địa được bán trên thị trường điện tử trong đại dịch Covid-19.

Từ khóa: Lòng trung thành khách hàng, niềm tin, chất lượng dịch vụ, tính vị chủng, rủi ro cảm nhận, thị trường điện tử, đại dịch Covid-19.

\section{CUSTOMER LOYALTY TOWARD DOMESTIC GOODS ON THE E-MARKETPLACES IN COVID-19 PANDEMIC}

\begin{abstract}
The outbreak of the Covid-19 pandemic has made customers worry about the spread of the disease as they buy the goods from international online store, as well as international freight has become more difficult. Consequently, customers have tended to switch to domestic goods from e-marketplaces. This study evaluated the effects of trust, ethnocentrism, service quality, perceived risk on customer loyalty toward domestic goods as shopping online on e-marketplaces. This research employed a mixed research method to achieve the research objectives. The results pointed out that trust, ethnocentrism, and service quality positively impact customer loyalty. Meanwhile, perceived risk negatively affects customer loyalty to domestic products in the e-marketplaces in the Covid-19 pandemic. Some managerial implications were proposed based on the research results to increase customer loyalty toward domestic goods, which were sold on the e-marketplaces in the Covid-19 pandemic.
\end{abstract}

Keywords: Customer loyalty, trust, service quality, ethnocentrism, perceived risk, e-marketplace, Covid19 pandemic.

\section{GIỚI THIỆU}

Thị trường điện tử (electronic marketplace) được đánh giá là một nền tảng tổ chức cho phép người bán gặp gỡ người mua và các bên tham gia trao đổi thông tin về giá cả và dịch vụ. Do đó, khách hàng dễ dàng lựa chọn những sản phẩm mong muốn từ nhiều người bán khác nhau, cả trong lẫn ngoài nước. Sự ra đời và phát triển của thị trường điện tử đã tạo ra những thuận lợi cho doanh nghiệp trong kinh doanh, tuy nhiên, đi kèm đó là những khó khăn về sự cạnh tranh giữa các doanh nghiệp ở thị trường này. Sự cạnh tranh diễn ra trên thị trường điện tử không chỉ là cuộc đối đầu giữa các doanh nghiệp cùng ngành mà còn là giữa doanh nghiệp trong nước và doanh nghiệp quốc tế. Với lợi thế giá rẻ, nhiều doanh nghiệp quốc tế, đặc biệt là doanh nghiệp Trung Quốc, đã chiếm lợi thế trên thị trường điện tử. Đối với thị trường điện tử nói riêng và thương mại điện tử nói chung, lòng trung thành trở thành một yếu tố sẽ đảm bảo sự tồn tại cho doanh nghiệp 
$[1,2]$. Tuy nhiên, việc xây dựng lòng trung thành của khách hàng trên thị trường trực tuyến sẽ khó khăn hơn, bởi vì khách hàng có quá nhiều lựa chọn, không chỉ mua hàng trong nước mà còn từ các gian hàng quốc tế trên thị trường điện tử. Palmatier và cộng sự (2006) đã đề xuất khung phân tích tổng hợp trung gian mối quan hệ (Relational Mediator Meta-Analytic Framework) để xây dựng mô hình đo lường lòng trung thành của khách hàng. Ngoài ra, Gan và cộng sư [3] cũng đã đề xuất lý thuyết mối quan hệ trực tuyến (Online relationship marketing) trong việc sử dụng các yếu tố tác động đến lòng trung thành của người tiêu dùng. Mô hình marketing mối quan hệ trực tuyến đã chỉ ra rằng niềm tin, sự cam kết, sự hài lòng mối quan hệ và chất lượng mối quan hệ là tiền đề của yếu tố lòng trung thành của khách hàng khi mua sắm trực tuyến [4]. Bên cạnh đó, lòng trung thành với các sản phẩm trong nước cũng phụ thuộc vào tính vị chủng của người tiêu dùng $[5,6]$. Đặc biệt, rủi ro cảm nhận khi mua hàng trực tuyến vẫn tồn tại khi khách hàng giao dịich trên thị trường trực tuyến $[7,8]$. Những rủi ro cảm nhận này có thể là nguyên nhân giảm ý định mua sắm trực tuyến [9] và lòng trung thành của khách hàng khi mua sắm trực tuyến [10].

Hiện tại, Việt Nam được đánh giá là một trong những thị trường điện tử phát triển nhanh nhất Đông Nam Á với tốc độ tăng trưởng bình quân hàng năm hơn $25 \%$, sự tăng trưởng đột phá của thị trường điện tử đã đưa Việt Nam trở thành một trong những thị trường tiềm năng nhất trong khu vực ASEAN [11]. Đại dịch Covid-19 khiến cho nhiều doanh nghiệp lẫn người bán lẻ trước đây chưa từng bán hàng trực tuyến, thì nay mở rộng việc kinh doanh thông qua kênh bán hàng trực tuyến, thúc đẩy quá trình chuyển đổi số của các doanh nghiệp [12]. Tại Việt Nam, đại dịch Covid-19 đã tác động mạnh đến thị trường kinh doanh nói chung. Qua khảo sát của iPrice Insights phối hợp cùng SimilarWeb, đối với 3 nền tảng thương mại điện tử hàng đầu là Tiki, Lazada, Sendo có lượng khách hàng giảm mạnh so với cùng kỳ và các quý cuối năm 2019. Chỉ có Shopee là nền tảng thương mại điện tử giảm vào quý 3 và quý 4 vào năm 2019 nhưng lấy lại đà vào quý 1 năm 2020 [13]. Covid-19 đang bùng phát trên thế giới cũng như Việt Nam ảnh hưởng mạnh đến việc lưu thông hàng hóa từ nước ngoài vào Việt Nam. Việc vận chuyển quốc tế trở nên khó khăn hơn, thời gian đặt hàng từ nước ngoài về tăng đáng kể. Các mặt hàng có thể bị giữ lại tại cửa khẩu do tình hình dịch diê̂n biến phức tạp hoặc có thể lâu hơn thời gian dự kiến do phải kiểm tra hàng hóa. Việc kiểm tra hàng cũng có thể phát sinh các rủi ro như hư hỏng hoặc nhầm hàng, mất hàng. Trong giai đoạn này, khách hàng đang có xu hướng chuyển sang lựa chọn các hàng hóa nội địa cho việc mua sắm trực tuyến từ các thị trường điện tử. Tuy nhiên, việc khách hàng chuyển sang mua sắm, mua nhiều hơn và duy trì lòng trung thành đối với các sản phẩm nội địa cần có sự đầu tư từ phía những người bán hàng trực tuyến trên các sàn giao dịch trực tuyến.

Do đó, nghiên cứu này sẽ đánh giá các tác động của niềm tin, tính vị chủng, chất lượng dịch vụ, rủi ro cảm nhận đến lòng trung thành của khách hàng đối với các hàng hóa nội địa khi mua sắm trực tuyến trên các sàn giao dịch điện tử trong đại dịch Covid-19. Các phần tiếp theo của nghiên cứu này bao gồm tổng cơ sở lý thuyết, phương pháp nghiển cứu, kết quả và thảo luận, kết luận.

\section{CƠ SỞ LÝ THUYẾT}

Lòng trung thành là một cam kết sâu sắc rằng khách hàng sẽ mua lại hoặc bảo trợ một sản phẩm hay dịch vụ ưa thích trong tương lai [14]. Do đó khách hàng sẽ mua lại cùng nhãn hiệu, bất chẩp ảnh hưởng của các tình huống phát sinh [15]. Tiếp đó, Ribbink và cộng sụ [16] cho rằng định nghĩa này cũng áp dụng cho lòng trung thành trực tuyến. Lòng trung thành đối với một trang thương mại điện tử mô tả thái độ tích cực và cam kết của khách hàng đối với trang thương mại điện tử, dẫn đến hành vi mua lại và không chuyển sang trang thương mại điện tử khác [17]. Khách hàng trung thành với một trang thương mại điện tử có xu hướng mua lại, nói tốt về trang thương mại điện tử và khuyến khích những người khác mua trên trang thương mại điện tử đó [18].

Thị trường điện tử được định nghĩa là hệ thống thông tin liên tổ chức, cho phép nhiều người mua và người bán cũng như các bên liên quan khác giao tiếp và giao dịch thông qua thị trường được hỗ trợ bởi các dịch vụ trực tuyến bổ sung [19]. Thị trường điện tử là một trung gian trực tuyến được thiết kế để tạo ra mối quan hệ giữa người mua và người bán, qua đó tạo điều kiện thuận lợi cho các giao dịch giữa họ. Ngoài ra, thị trường điện tử cũng thường tạo điều kiện thuận lợi cho các hoạt động giao dịch giữa các đối tác chưa có tương tác trước đó liên quan đến người mua, người bán và nhà cung cấp thị trường điện tử [20]. Ngày nay, nhiều công ty đang trải nghiệm giao dịch trên thị trường điện tử để tăng tính hiệu quả trong kinh doanh, và 
hầu hết các công ty đều hài lòng khi họ tạo gian hàng, cũng như tương tác với khách hàng trên thị trường điện tử [21].

Nghiên cứu này dựa trên lý thuyết mối quan hệ trực tuyến của Gan và cộng sư [3] và khung phân tích tổng hợp trung gian mối quan hệ được đề xuất bởi Palmatier và cộng sự [22] để xây dựng mối quan hệ giữa các cấu trúc trong mô hình nghiên cứu. Marketing mối quan hệ trực tuyến là hoạt động thông qua việc sử dụng các tính năng tương tác của website, các công cụ hỗ trợ Internet để thiết lập và phát triển các mối quan hệ lâu dài, hai bên cùng có lợi với khách hàng [3]. Các thuộc tính của bán hàng trực tuyến trên các trang thương mại điện tử thường được khai thác thông qua các hoạt động như tham gia mua sắm, tương tác và cộng tác của khách hàng với mục đích xây dựng mối quan hệ với khách hàng trong dài hạn [23]. Dựa trên khung phân tích tổng hợp trung gian mới quan hệ được đề xuất bởi Palmatier và cộng sụ [22], mô hình marketing mối quan hệ trực tuyến đã chỉ ra rằng lòng trung thành của khách hàng đối với một người bán hàng trực tuyến đến từ niềm tin, sự cam kết, sự hài lòng mối quan hệ và chất lượng mối quan hệ [4]. Bên cạnh đó, lòng trung thành với các sản phẩm trong nước cũng phụ thuộc vào tính vị chủng của người tiêu dùng $[5,6]$. Đặc biệt, mua trực tuyến vẫn mang lại một số bất an vì rủi ro cảm nhận vẫn tồn tại khi giao dịch trên thị trường trực tuyến $[7,8]$, rủi ro cảm nhận này có thể là nguyên nhân giảm lòng trung thành của khách hàng khi mua sắm trực tuyến [10].

Niềm tin sẽ ảnh hưởng đến mức độ sã̃n sàng mua hàng trực tuyến của khách hàng. Các khách hàng trực tuyến sẽ thường tránh xa các nhà cung cấp trên thị trường điện tử nếu các nhà cung cấp đó không tạo đủ niềm tin cho họ [24]. Ngược lại, nếu niềm tin càng cao sẽ có tác động trực tiếp và tích cực đến lòng trung thành của khách hàng [25]. Hơn nữa, niềm tin của khách hàng còn là tiền đề tốt nhất để giải thích sự trung thành của khách hàng đối với các nhà bán lẻ trực tuyến [26]. Do đó, niềm tin được coi là yếu tố chính góp phần tạo nên lòng trung thành đối với người bán trên thị trường trực tuyến nói chung. Nếu khách hàng có niềm tin đối với chất lượng hàng hóa nội địa, hoặc người bán trong nước, họ sẽ tiếp tục mua hàng và trung thành với loại hàng hóa này trên thị trường điện tử. Do đó, nghiên cứu đề xuất giả thuyết $\mathrm{H} 1$ như sau:

H1: Niềm tin của khách hàng có tác động đồng biến đến lòng trung thành khách hàng đối với các sản phẩm trong nước trên thị trường điện tư.

Trong thị trường trực tuyến, chất lượng dịch vụ được định nghĩa là mức độ mà một trang thương mại điện tử tạo điều kiện thuận lợi và hiệu quả cho việc mua sắm [27]. Chất lượng dịch vụ trên thị trường điện tử được xem xét trên các đánh giá và nhận định tổng thể của khách hàng về chất lượng của việc cung cấp dịch vụ trên thị trường điện tử [26]. Các nghiên cứu trước đây cũng đã xác nhận và cho thấy mối quan hệ giữa chất lượng dịch vụ và lòng trung thành của khách hàng $[28,29]$. Do đó, giả thuyết $\mathrm{H} 2$ được đề xuất như sau:

H2: Chất luợng dịch vu có tác động đồng biến đến lòng trung thành khách hàng đối với các sản phẩm trong nước trên thị trường điện tư.

Tính vị chủng của một khách hàng thể hiện họ sẽ không bị thu hút bởi các sản phẩm sản xuất ở nước ngoài, và thừa nhận một cách sâu sắc các sản phẩm sản xuất trong nước [30]. Những người tiêu dùng có tính vị chủng cao thậm chí có thể phản đối các sản phẩm do nước ngoài sản xuất đơn giản vì đó là "sản phẩm nước ngoài”. Trong một số trường hợp, người tiêu dùng sẽ không tập trung đánh giá sản phẩm về chất lượng, mà chỉ quan tâm quốc gia xuất xứ [6]. Tính vị chủng của khách hàng tập trung vào trách nhiệm và đạo đức khi mua các sản phẩm; do đó, họ sẽ thể hiện lòng trung thành đối với các sản phẩm được sản xuất trong nước [5]. Shimp và Sharma [30] cho rằng tính vị chủng khiến khách hàng có thể đánh giá cao các thuộc tính và chất lượng tổng thể của các sản phẩm trong nước, đồng thời đánh giá thấp chất lượng của các sản phẩm nước ngoài. Tính vị chủng của khách hàng có thể ảnh hưởng đến quyết định mua hàng [5]. Do đó, giả thuyết H3 được thiết lập:

H3: Tính vị chủng của khách hàng có tác động đồng biến đến lòng trung thành khách hàng đối với các sản phẩm trong nước trên thị truờng điện tư.

Rủi ro cảm nhận thường được định nghĩa là sự đánh giá chủ quan về những hậu quả không chắc chắn về tài chính, thông tin riêng tư, và vật chất khi trải nghiệm tiêu dùng [7]. Rủi ro cảm nhận là mối đe dọa đối với sự thành công của hoạt động tiếp thị, vì nó khiến người tiêu dùng tập trung vào khả năng mất nguồn lực hơn là tin tưởng và gắn bó lâu dài với doanh nghiệp nếu nhận ra có rủi ro [7]. Do đó, rủi ro cảm nhận có thể tác động tiêu cực đến hành vi mua hàng. Thông tin không nhất quán, hoặc tính vô hình của giao dịch 
làm tăng tính không chắc chắn khi giao dịch trực tuyến [31], Rủi cảm nhận phải được loại bỏ để đạt được lòng trung thành của khách hàng [32]. Do đó, giả thuyết $\mathrm{H} 4$ được thiết lập:

H4: Rủi ro cảm nhận có tác động nghịch biến đến lòng trung thành khách hàng đối với các sản phẩm nội địa trên thị trường điện tư.

Từ các lý luận trên, nghiên cứu này đề xuất mô hình nghiên cứu được trình bày như hình 1 .

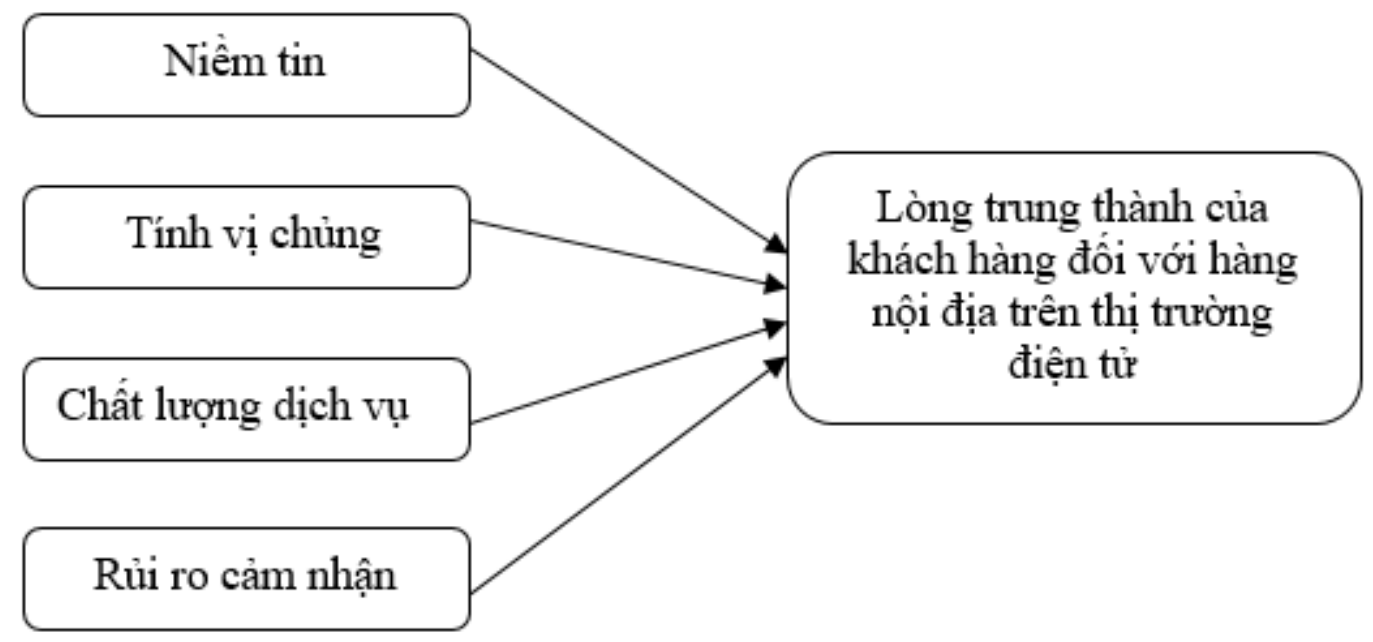

Hình 1: Mô hình nghiên cứu

\section{PHƯƠNG PHÁP NGHIÊN CÚU}

Nghiên cứu sử dụng phương pháp nghiên cứu hỗn hợp, bao gồm nghiên cứu định tính và nghiên cứu định lượng để đạt được các mục tiêu nghiên cứu. Nghiên cứu định tính được thực hiện thông qua phỏng vấn nhóm tập trung để thu thập ý kiến của các thành viên. Cuộc phỏng vấn nhóm tập trung bao gồm 12 thành viên có kinh nghiệm mua hàng trên thị trường điện tử. Buổi thảo luận được tiến hành dưới sự chủ trì của tác giả với dàn bài thảo luận nhóm được chuẩn bị sẵn. Kết quả là các chỉ mục quan sát đã được điều chỉnh để mang lại giá trị khảo sát cao ở phần nghiên cứu định lượng, phù hợp với bối cảnh Việt Nam ở thời điểm Covid-19. Sau khi hoàn thành cuộc phỏng vấn, bước tiếp theo là tiến hành nghiên cứu định lượng.

Nghiên cứu định lượng với quy mô mẫu nghiên cứu là 210 khách hàng, thông qua phương pháp thu thập dữ liệu có mục đích. Cuộc khảo sát được thực hiện đối với các khách hàng đang mua sắm trên thị trường điện tử thông qua bảng câu hỏi khảo sát trực tuyến được xây dựng bằng Google biểu mẫu. Liên kết của bảng câu hỏi được gửi qua thư điện tử của các đáp viên có mối quan hệ với các thành viên nhóm nghiên cứu, và đặt trên trang mạng xã hội của các thành viên nhóm nghiên cứu để bạn bè họ có thể trả lời. Trong đó, bảng câu hỏi có những câu hỏi sàng lọc để có được những người khảo sát đạt yêu cầu (như đang có mua hàng trực tuyến trên các thị trường điện tử như Tiki, Lazada, Shopee hay không? Mức độ mua hàng như thế nào?). Những đáp viên đang mua hàng trực tuyến trên các sàn giao dịch điện tử, và có mức độ mua hàng thường xuyên trong 3 tháng gần nhất sẽ thỏa yêu cầu trả lời bảng câu hỏi. Các chỉ mục của các cấu trúc nghiên cứu dựa trên các nghiên cứu trước đây, được điều chỉnh thông qua nghiên cứu định tính và được trình bày trong phụ lục 1 . Thang đo Likert 5 cấp bậc từ 1 đến 5 được sử dụng để đo các cấu trúc quan sát trong phụ lục 1 (với 1 . Hoàn toàn không đồng ý - 5. Hoàn toàn đồng ý). Dữ liệu thu thập được xử lý, phân tích trên phần mềm SPSS 26.0. Bảng 1 chỉ ra các cấu trúc nghiên cứu, số lượng chỉ mục và nguồn tham khảo của thang đo.

Bảng 1. Bảng tổng hợp các thang đo được sử dụng trong nghiên cứu

\begin{tabular}{|l|c|l|}
\hline \multicolumn{1}{|c|}{ Yếu tố } & Số lượng chỉ mục & \multicolumn{1}{|c|}{ Nguồn tham khảo } \\
\hline Niềm tin (MOT) & 5 & \multirow{2}{*}{ Yee và Faziharudean [33] } \\
\hline Chất lượng dịch vụ (MSQ) & 6 & Abdolvand và cộng sự [5] \\
\hline Tính vị chủng (MCE) & 7 & Jin và cộng sự [10] \\
\hline Rủi ro cảm nhận (MPR) & 3 & Yee và Faziharudean [33] \\
\hline Lòng trung thành khách hàng (MCL) & 5 & \multicolumn{2}{|c|}{} \\
\hline
\end{tabular}




\section{KẾT QUẢ VÀ THẢO LUẬN}

Mẫu nghiên cứu được mô tả trong bảng 2. Về giới tính, số lượng nữ tham gia là 114 đáp viên, chiếm 54,29). Ngoài ra, độ tuổi tập trung trong khảo sát là 22-25 tuổi, chiếm 69,53\%. Về nghề nghiệp tham gia khảo sát, có 87 đáp viên đang là sinh viên, chiếm $41,1 \%$, tiếp theo là nhân viên văn phòng, chiếm 33,3\%. Các kết quả thống kê mô tả mẫu nghiên cứu cho thấy mẫu có tính đại diện khi có sự phù hợp về giới tính, độ tuổi, và nghề nghiệp trong mua sắm trực tuyến theo báo cáo chung của Cục thương mại điện tử, Bộ Công Thương [34].

Bảng 2. Thống kê mô tả mẫu

\begin{tabular}{|l|l|c|c|}
\hline \multicolumn{1}{|c|}{ Tiêu chí } & & Số lượng & Phần trăm \\
\hline \multirow{2}{*}{ Giới tính } & Nam & 96 & 45,71 \\
& Nũ̃ & 114 & 54,29 \\
\hline \multirow{2}{*}{ Tuổi } & $21-25$ & 146 & 69,52 \\
& $26-38$ & 64 & 30,48 \\
\hline \multirow{5}{*}{ Nghề nghiệp } & Sinh viên & 87 & 41,1 \\
& Nhân viên văn phòng & 70 & 33,3 \\
& Nội trợ & 9 & 4,3 \\
& Cồng nhân & 11 & 5,2 \\
& Quản lý & 15 & 7,1 \\
& Khác & 18 & 8,6 \\
\hline
\end{tabular}

Theo bảng 3 , các thang đo đáng tin cậy để phân tích trong nghiên cứu này. Trong đó, độ tin cậy của thang đo thấp nhất là 0,767 , cao hơn 0,7 [35]. Kết quả phân tích nhân tố khám phá (EFA) trong bảng 3 cho thấy các hạng mục nghiên cứu được chia thành 5 nhân tố với hệ số $\mathrm{KMO}=0,855>0,5$ và Sig. của kiểm định Bartlett $=0,000<0,05$ [36]. Do đó, phân tích nhân tố là phù hợp. Hơn nữa, hệ số tải nhân tố của tất cả các mục đều lớn hơn 0,5 . Do đó, nghiên cứu này đã xác định 4 yếu tố độc lập, bao gồm: (1) tính vị chủng, (2) niềm tin, (3) chất lượng dịch vụ, (4) rủi ro cảm nhận, và một yếu tố phụ thuộc là lòng trung thành của khách hàng đối với sản phẩm nội địa trên thị trường điện tử trong đại dịch Covid-19.

Bảng 3. Cronbach's Alpha và EFA

\begin{tabular}{|l|c|c|}
\hline \multicolumn{1}{|c|}{ Yếu tố } & Cronbach's Alpha & Hệ số tải nhân tố \\
\hline Niềm tin (MOT) & 0,859 & {$[0,855-0,862]$} \\
\hline Chất lượng dịch vụ (MSQ) & 0,831 & {$[0,811-0,783]$} \\
\hline Tính vị chủng (MCE) & 0,794 & {$[0,760-0,679]$} \\
\hline Rủi ro cảm nhận (MPR) & 0,767 & {$[0,689-0,754]$} \\
\hline Lòng trung thành khách hàng (MCL) & 0,824 & {$[0,764-0,806]$} \\
\hline
\end{tabular}

Kaiser-Meyer-Olkin $=0.855$

Bartlett's Test of Sphericity, Sig. $=0.00$

Theo bảng 4, hệ số VIF của các biến đều nhỏ hơn 2 (lớn nhất là 1,659). Do đó, hiện tượng đa cộng tuyến xảy ra giữa các biến độc lập trong mô hình này là nhỏ, không ảnh hưởng đáng kể đến kết quả hồi quy. Hệ số $\mathrm{R}^{2}$ điều chỉnh cho biết mức độ phần trăm biến thiên của biến phụ thuộc được giải thích bởi các biến độc lập. Kết quả hồi quy cho thấy $\mathrm{R}^{2}$ điều chỉnh là $54,9 \%$; do đó, $54,9 \%$ sự thay đổi của lòng trung thành là do 4 yếu tố nghiên cứu gây ra, các yếu tố khác ngoài mô hình giải thích $45,1 \%$ còn lại.

Bảng 4: Kết quả hồi quy

\begin{tabular}{|c|c|c|c|c|c|c|c|c|}
\hline & \multicolumn{2}{|c|}{$\begin{array}{c}\text { Hệ số chưa chuẩn } \\
\text { hóa }\end{array}$} & \multirow{2}{*}{$\begin{array}{c}\begin{array}{c}\text { Hệ số chuẩn } \\
\text { hóa }\end{array} \\
\text { Beta }\end{array}$} & \multirow{2}{*}{ Sig. } & \multicolumn{2}{|c|}{$\begin{array}{l}\text { Kiểm định đa cộng } \\
\text { tuyến }\end{array}$} & \multicolumn{2}{|c|}{$\begin{array}{l}\text { Kiểm định phương sai thay } \\
\text { đổi }\end{array}$} \\
\hline & B & $\begin{array}{l}\text { Sai số } \\
\text { chuẩn }\end{array}$ & & & Tolerance & VIF & $\mathrm{r}$ & $\begin{array}{c}\text { Sig. } \\
\text { r(ABSRES) }\end{array}$ \\
\hline Hằng số & 1,099 & 0,211 & & 0,000 & & & & \\
\hline MCE & 0,219 & 0,045 & 0,294 & 0,000 & 0,603 & 1,659 & 0,045 & 0,482 \\
\hline MOT & 0,433 & 0,056 & 0,455 & 0,000 & 0,627 & 1,595 & 0,017 & 0,827 \\
\hline MPR & $-0,074$ & 0,028 & $-0,126$ & 0,008 & 0,978 & 1,022 & $-0,061$ & 0,812 \\
\hline MSQ & 0,136 & 0,058 & 0,136 & 0,020 & 0,636 & 1,572 & 0,052 & 0,385 \\
\hline
\end{tabular}


Durbin-Watson $=1,659$

$\mathrm{F}=63,637 ;$ Sig. $=0,000$

$\mathrm{R}^{2}$ điều chỉnh $=0,549$

Theo bảng 4, giá trị Durbin-Watson $(\mathrm{d})=1,659$, với kích thước mẫu $\mathrm{N}=210$, ta có $1,344<1,659<(4-$ $1,246)=2,754$ nên thỏa mãn điều kiện; do đó, không có sự tương quan chuỗi bậc nhất trong mô hình hồi quy bội. Tất cả giá trị Sig. mối tương quan hạng giữa ABSRES với các biến độc lập đều lớn hơn 0,05 , do đó phương sai phần dư là đồng nhất, giả định phương sai không đổi không bị vi phạm. Qua bảng phân tích ANOVA cho thấy tỷ lệ $\mathrm{F}=63,637$ và có $\mathrm{Sig} .=0,000(\mathrm{Sig}$. $\leq 0,05)$. Mô hình hồi quy có ý nghĩa theo dữ liệu thu thập được và các biến được đưa vào có ý nghĩa thống kê, với mức ý nghĩa $5 \%$. Hệ số Beta cho thấy mức độ ảnh hưởng của bốn biến độc lập đến biến phụ thuộc và tầm quan trọng của từng biến độc lập trong mô hình lần lượt là: $\mathrm{MOT}=0,455, \mathrm{MCE}=0,294, \mathrm{MSQ}=0,136, \mathrm{MPR}=-0,126$. Từ kết quả phân tích ta có mô hình hồi quy:

$$
M C L=1,099+0,433 * M O T+0,219 * M C E+0,136 * M S Q-0,074 * M P R
$$

\section{THẢO LUẬN KẾT QUẢ NGHIÊN CÚU}

Thứ nhất, niềm tin là các yếu tố chủ yếu nâng cao lòng trung thành của khách hàng khi mua các sản phẩm nội địa trên thị trường điện tử trong thời kỳ đại dịch Covid-19. Niềm tin khách hàng đã tạo nên mức độ trung thành cao của khách hàng với các sản phẩm nội địa được bán trên thị trường điện tử với Beta $=0,455$ $($ Sig. $=0,000)$. Niềm tin là một động lực rất quan trọng đối với lòng trung thành [37]. Trao đổi trực tuyến được coi là hoạt động rất rủi ro do thiếu sự tiếp xúc trực tiếp giữa khách hàng và nhân viên bán hàng. Những khách hàng không tin tưởng vào một nhà cung cấp trực tuyến sẽ ít có xu hướng giao dịch với người bán trực tuyến [38]. Ngoài ra, nếu khách hàng không tin tưởng vào một doanh nghiệp trực tuyến, họ sẽ không trung thành dù họ có thể hài lòng về sản phẩm đã mua [37, 39].

Thứ hai là tính vị chủng của khách hàng với Beta =0,294 (Sig. = 0,000). Tính vị chủng là một yếu tố quan trọng thúc đẩy hành vi và thái độ lòng trung thành của khách hàng đối với các sản phẩm trên thị trường điện tử $[5,6]$. Tính vị chủng trong tiêu dùng quan tâm đến việc ưa chuộng các sản phẩm trong nước và không đánh giá cao các sản phẩm do nước ngoài sản xuất [40]. Người tiêu dùng có tính vị chủng cao xem việc mua các sản phẩm nước ngoài là vô đạo đức hoặc không phù hợp, vì nó gây tổn hại cho nền kinh tế trong nước, không yêu nước và gây mất việc làm cho người lao động trong nước [30], do đó, họ sẽ có xu hướng trung thành với các sản phẩm được sản xuất bởi các doanh nghiệp trong nước. Đặc biệt, trong bối cảnh Covid-19, nhiều doanh nghiệp trong nước không thể xuất khẩu hàng hóa ra nước ngoài, vì vậy, các khách hàng có tính vị chủng cao càng thể hiện lòng trung thành cao hơn thông qua việc tiếp tục mua, mua nhiều hơn bình thường, và thậm chí là khuyến khích bạn bè, người thân mua các sản phẩm nội địa được bán trên các sàn giao dịch thương mại điện tử.

Thứ ba là chất lượng dịch vụ dịch vụ với Beta $=0,136$ (Sig. $=0,020)$. Từ kết quả nghiên cứu cho thấy chất lượng dịch vụ có tác động tích cực đến lòng trung thành của khách hàng [41-43]. Kết quả cho thấy, nếu chất lượng dịch vụ của các doanh nghiệp bán hàng hóa có nguồn gốc, xuất xứ trong nước cao thì khách hàng sẽ tiếp tục mua những sản phẩm này trong tương lai [44]. Do đó, nghiên cứu còn cho thấy khi chất lượng dịch vụ cao thì lòng trung thành của khách hàng cũng được nâng cao $[45,46]$. Những khách hàng trực tuyến sẽ truyền miệng tốt về các sản phẩm nội địa được bán bởi các nhà cung cấp trực tuyến với chất lượng dịch vụ tốt [47]. Bên cạnh đó, nhiều khách hàng vẫn còn lo lắng về vấn đề sẽ không nhận được chất lượng dịch vụ tốt nhất khi mua hàng trong nước do sự chậm trễ trong phản hồi, hoặc chưa có minh bạch trong việc xử lý các lỗi trong giao dịch.

Cuối cùng, nghiên cứu cho thấy mối quan hệ nghịch biến giữa rủi ro cảm nhận và lòng trung thành của khách hàng $($ Beta $=-0,126$, Sig. $=0,008)$. Kết quả nghiên cứu phản ánh đúng với bản chất tâm lý của khách hàng nghĩa là tâm lý ngại rủi ro khi giao dịch trên thị trường điện tử [10]. Marakanon và Panjakajornsak [48] đã chỉ ra rằng rủi ro chức năng, rủi ro hoạt động và rủi ro tài chính sẽ ảnh hưởng đến lòng trung thành của khách hàng. Ngoài ra, Huy Tuu và cộng sụ [49] cũng tìm ra được rủi ro cảm nhận đóng vai trò trung gian trong mối quan hệ giữa sự hài lòng và lòng trung thành của khách hàng. 


\section{KÉT LUẬN VÀ MỘT SỐ HÀM Ý QUẢN TRI}

Nghiên cứu này đã xác định các yếu tố ảnh hưởng đến lòng trung thành của khách hàng khi mua các sản phẩm trong nước trên thị trường điện tử trong đại dịch Covid-19 thông qua áp dụng phương pháp nghiên cứu định tính và định lượng với kích thước mẫu quan sát là 210 để kiểm tra một cấu trúc tuyến tính. Trong đó, niềm tin của khách hàng, chất lượng dịch vụ, rủi ro cảm nhận và tính vị chủng ảnh hưởng đến lòng trung thành của khách hàng khi mua các sản phẩm trong nước trên thị trường điện tử đại dịch Covid-19. Dựa trên kết quả nghiên cứu, một số hàm ý quản trị được đề xuất cho các doanh nghiệp kinh doanh trên thị trường điện tử như sau:

Trong tình hình dịch Covid-19 đang diễn biến phức tạp, hoạt động giao nhận hàng hóa cũng gặp nhiều khó khăn do các chỉ thị giãn cách xã hội và phong tỏa các khu vực. Vì vậy, các doanh nghiệp bán hàng nội địa trên thị trường điện tử nên có các biện pháp để tránh rủi ro phát sinh khi giao dịch trực tuyến. Doanh nghiệp bán hàng nội địa cần có sự liên kết với các doanh nghiệp vận chuyển để hạn chế tối đa việc nhân viên giao hàng giao chậm hàng. Doanh nghiệp cần phải nắm bắt kịp thời những thay đổi trong quá trình giao hàng để hàng hóa có thể đến tay người tiêu dùng kịp thời và an toàn. Ngoài ra, doanh nghiệp bán hàng trên thị trường điện tử cần đảm bảo chất lượng hàng hóa để giảm sự lo sợ của khách hàng thông qua việc lựa chọn nhà cung cấp có uy tín, hoặc kiểm tra hàng hóa trước khi giao đến cho khách hàng.

Dịch bệnh Covid-19 kéo dài sẽ làm cho nền kinh tế Việt Nam suy giảm, chính vì vậy nhiều khách hàng cũng giảm thu nhập trong cuộc sống. Cụ thể, doanh nghiệp nội địa nên có chương trình tư vấn bán hàng trực tuyến trên sàn giao dịch trực tuyến, tư vấn qua hệ thống chăm sóc khách hàng, tăng cường bố trí nhân viên để giải đáp thắc mắc, khiếu nại của khách hàng nhanh chóng. Qua đó, doanh nghiệp sẽ gia tăng được niềm tin của khách hàng trong bối cảnh vừa áp lực bởi dịch bệnh, vừa giảm được sự bực bội khi không được chăm sóc tức thời hoặc đúng mức sau khi mua hàng. Ngoài ra, doanh nghiệp cần cung cấp đầy đủ thông tin xuất xứ của sản phẩm để tạo lòng tin và giảm lo lắng cho khách hàng khi mua các sản phẩm không biết nguồn gốc hoặc nhầm lẫn với sản phẩm có xuất xứ từ các nước đang có dịch bệnh như Trung Quốc, Ân Độ.

Bên cạnh đó, các doanh nghiệp quản trị thị trường điện tử phối hợp nhà bán lẻ nên ưu tiên mua bán sản phẩm nội địa trên thị trường điện tử. Ngoài ra, để thực hiện công tác giáo dục hành vi của người tiêu dùng, các sàn thương mại điện nên có các chương trình khuyến mãi cho hàng nội địa. Doanh nghiệp kinh doanh trên thị trường điện tử cần củng cố chất lượng, và đưa ra giá cả phù hợp nhằm thúc đẩy lòng trung thành của khách hàng đối với hàng Việt Nam trên thị trường điện tử. Vì ảnh hưởng bởi đại dịch Covid-19 nên vấn đề giãn cách xã hội, cách ly hay là vấn đề phải làm việc, học tập trực tuyến tại nhà dẫn đến thời gian truy cập mua sắm trên thị trường trực tuyến cũng thay đổi, vậy nên doanh nghiệp cần mở rộng các khung giờ quảng cáo, tiếp thị hợp lý nhất nhẳm tăng tiếp cận sản phẩm nội địa đến khách hàng một cách tốt nhất.

Ngoài ra, doanh nghiệp cần phải thường xuyên cập nhật tình hình diễn biến của đại dịch Covid-19 để ước lượng, xác định, thương lượng và cam kết thời gian giao hàng đến khách hàng một cách chính xác nhất khi kinh doanh trực tuyến. Sự cam kết về thời gian giao nhận hàng đến khách hàng đúng thời hạn giúp gia tăng niềm tin đối với khách hàng cũng như giúp tăng chất lượng dịch vụ của doanh nghiệp khi kinh doanh trên thị trường trực tuyến trong thời kỳ đại dịch Covid-19 diễn ra hết sức phức tạp.

Mặc dù đã có nhiều nỗ lực, nghiên cứu vẫn có một số hạn chế. Đầu tiên, do thời gian và nguồn lực có hạn nên số lượng mẫu nghiên cứu còn hạn chế. Cụ thể, nghiển cứu tập trung chủ yếu vào khách hàng trẻ từ $21-$ 38 tuổi tại Thành phố Hồ Chí Minh, đây là khách hàng có xu hướng mua hàng trực tuyến cao từ các chợ điện tử. Các nghiên cứu tiếp theo có thể khắc phục những hạn chế này bằng cách mở rộng nghiên cứu đến các nhóm khách hàng ở các độ tuổi khác nhau hoặc sinh sống ở nhiều khu vực, địa điềm khác nhau. Ngoài ra, kết quả nghiên cứu chỉ ra 4 nhân tố ảnh hưởng đến lòng trung thành của khách hàng khi mua sắm trên các sàn giao dịch thương mại điện tử $\left(\mathrm{R}^{2}\right.$ điều chỉnh $\left.=54,9 \%\right)$, chỉ ra niềm tin của khách hàng, chất lượng dịch vụ, rủi ro cảm nhận và tính vị chủng. Do đó, các nghiên cứu tiếp theo có thể mở rộng mô hình nghiên cứu với một số cấu trúc phù hợp như lợi ích cảm nhận, chương trình khuyến mãi, sự tiện lợi để gia tăng giá trị $\mathrm{R}^{2}$ điều chỉnh và độ tin cậy của kết quả nghiên cứu. 


\section{TÀI LIỆU THAM KHẢO}

[1] K. Purani, D. S. Kumar, và S. Sahadev. (2019), e-Loyalty among millennials: Personal characteristics and social influences. Journal of Retailing and Consumer Services, Vol. 48, No., 215-223.

[2] B. T. Khoa. (2020), Electronic Loyalty in the Relationship between Consumer Habits, Groupon Website Reputation, and Online Trust: A Case of the Groupon Transaction. Journal of Theoretical and Applied Information Technology, Vol. 98, No. (24), 3947-3960.

[3] L. Gan, C. Sim, H. Tan, và J. Tna. (2007), Online relationship marketing by Singapore hotel websites. Journal of Travel \& Tourism Marketing, Vol. 20, No. (3-4), 1-19.

[4] V. Verma, D. Sharma, và J. Sheth. (2015), Does relationship marketing matter in online retailing? A metaanalytic approach. Journal of the Academy of Marketing Science, Vol. 44, No. (2), 206-217. doi:10.1007/s11747-015-0429-6

[5] M. A. Abdolvand, M. Farzin, A. M. Asl, và M. Sadeghian. (2016), The effect of consumer awareness on consumer ethnocentrism and loyalty regards to the function of international brands. International Journal of Life science and Pharma Research, Vol. Special issue, No. (2), 102-114.

[6] C. Makanyeza. (2015), Consumer awareness, ethnocentrism and loyalty: An integrative model. Journal of International Consumer Marketing, Vol. 27, No. (2), 167-183.

[7] M. S. Featherman và P. A. Pavlou. (2003), Predicting e-services adoption: a perceived risk facets perspective. International Journal of Human-Computer studies, Vol. 59, No. (4), 451-474. doi:doi.org/10.1016/s10715819(03)00111-3

[8] A. B. Ozturk, K. Nusair, F. Okumus, và D. Singh. (2017), Understanding mobile hotel booking loyalty: an integration of privacy calculus theory and trust-risk framework. Information Systems Frontiers, Vol. 19, No. (4), 753-767.

[9] B. T. Khoa. (2018), Ảnh hưởng của rủi ro cảm nhận đến ý định mua hàng trực tuyến của khách hàng tại TP. Hồ Chí Minh. Tap chí Khoa học và Công nghệ (IUH), Vol. 34, No. (04), 87-97. doi:10.46242/jstiuh.v34i04.414

[10] N. Jin, N. D. Line, và J. Merkebu. (2016), The impact of brand prestige on trust, perceived risk, satisfaction, and loyalty in upscale restaurants. Journal of Hospitality Marketing \& Management, Vol. 25, No. (5), 523546.

[11] Nguyễn Hạnh. (2020). Nâng cao chất luợng cuộc vận động "Nguời Việt Nam uu tiên dùng hàng Việt Nam". Truy cập từ: https://congthuong.vn/nang-cao-chat-luong-cuoc-van-dong-nguoi-viet-nam-uu-tien-dunghang-viet-nam-139144.html

[12] Vũ Duy Nguyên. (2020), Phát triển thương mại điện tử xuyên biên giới hậu Covid-19 và gợi mở chính sách cho Việt Nam. Tạp chí Tài chính Vol. 2, No. (6/2020).

[13] Ngọc Anh. (2021). iPrice Group: Tổng kết Thuơng Mại Điện Tử Việt Nam năm 2020 huoóng đến 2021. Truy cập từ: https://advertisingvietnam.com/iprice-group-tong-ket-thuong-mai-dien-tu-viet-nam-nam-2020huong-den-2021-p16303

[14] B. T. Khoa và H. M. Nguyen. (2020), Electronic Loyalty In Social Commerce: Scale Development and Validation. Gadjah Mada International Journal of Business, Vol. 22, No. (3), 275-299. doi:10.22146/gamaijb.50683

[15] R. L. Oliver. (1999), Whence consumer loyalty? Journal of Marketing, Vol. 64, No. (4), 33-44. doi:10.1177/00222429990634s105

[16] D. Ribbink, A. C. R. van Riel, V. Liljander, và S. Streukens. (2004), Comfort your online customer: quality, trust and loyalty on the internet. Managing Service Quality: An International Journal, Vol. 14, No. (6), 446456. doi:10.1108/09604520410569784 
[17] T. S. Vijay, S. Prashar, và V. Sahay. (2019), The Influence of Online Shopping Values and Web Atmospheric Cues on E-Loyalty: Mediating Role of E-Satisfaction. Journal of theoretical and applied electronic commerce research, Vol. 14, No. (1), 1-15.

[18] S. A. Pratminingsih, C. Lipuringtyas, và T. Rimenta. (2013), Factors influencing customer loyalty toward online shopping. International Journal of Trade, Economics and Finance, Vol. 4, No. (3), 104-110.

[19] E. Turban, J. Whiteside, D. King, và J. Outland, Introduction to electronic commerce and social commerce. Cham, Switzerland: Springer, 2017.

[20] H. H. Chang và K. H. Wong. (2010), Adoption of e-procurement and participation of e-marketplace on firm performance: Trust as a moderator. Information \& management, Vol. 47, No. (5-6), 262-270.

[21] M. Rask và H. Kragh. (2004), Motives for e-marketplace participation: differences and similarities between buyers and suppliers. Electronic Markets, Vol. 14, No. (4), 270-283.

[22] R. W. Palmatier, R. P. Dant, D. Grewal, và K. R. Evans. (2006), Factors Influencing the Effectiveness of Relationship Marketing: A Meta-Analysis. Journal of Marketing, Vol. 70, No. (4), 136-153. doi:10.1509/jmkg.70.4.136

[23] T. Ahn, M. Hong, và P. M. Pedersen. (2014), Effects of perceived interactivity and web organization on user attitudes. European sport management quarterly, Vol. 14, No. (2), 111-128.

[24] K. Boonlertvanich. (2019), Service quality, satisfaction, trust, and loyalty: the moderating role of main-bank and wealth status. International Journal of Bank Marketing, Vol. 37, No. (1), 278-302. doi:10.1108/ijbm-022018-0021

[25] B. T. Khoa. (2020), The Impact of the Personal Data Disclosure's Tradeoff on the Trust and Attitude Loyalty in Mobile Banking Services. Journal of Promotion Management, Vol. 27, No. (4), 585-608. doi:10.1080/10496491.2020.1838028

[26] M. Al-dweeri Rami, A. Ruiz Moreno, L. Montes Francisco Javier, M. Obeidat Zaid, và M. Al-dwairi Khaldoon. (2019), The effect of e-service quality on Jordanian student's e-loyalty: an empirical study in online retailing. Industrial Management \& Data Systems, Vol. 119, No. (4), 902-923. doi:10.1108/IMDS12-2017-0598

[27] A. Parasuraman, V. A. Zeithaml, và L. L. Berry. (1988), Servqual: A multiple-item scale for measuring consumer perception of service quality. Journal of retailing, Vol. 64, No. (1), 12-40.

[28] M. M. Shafiee và N. A. Bazargan. (2018), Behavioral customer loyalty in online shopping: the role of Eservice quality and E-recovery. Journal of Theoretical and Applied Electronic Commerce Research, Vol. 13, No. (1), 26-38.

[29] R. M. Al-dweeri, A. Ruiz Moreno, F. J. L. Montes, Z. M. Obeidat, và K. M. Al-dwairi. (2019), The effect of e-service quality on Jordanian student's e-loyalty: an empirical study in online retailing. Industrial Management \& Data Systems, Vol. 119, No. (4), 902-923.

[30] T. A. Shimp và S. Sharma. (1987), Consumer ethnocentrism: construction and validation of the CETSCALE. Journal of marketing research, Vol. 24, No. (3), 280-289.

[31] G. S. Milan, S. Bebber, và D. Eberle. (2015), Information quality, distrust and perceived risk as antecedents of purchase intention in the online purchase context. Journal of Management Information System and ECommerce, Vol. 2, No. (2), 111-129.

[32] M. Grieger. (2003), Electronic marketplaces: A literature review and a call for supply chain management research. European Journal of Operational Research, Vol. 144, No. (2), 280-294. doi:10.1016/s03772217(02)00394-6

[33] B. Y. Yee và T. Faziharudean. (2010), Factors affecting customer loyalty of using Internet banking in Malaysia. Journal of Electronic Banking Systems, Vol. 2010, No. (2010), 1-21. 
[34] IDEA. (2020). Báo cáo Thương mại điện tử Việt Nam năm 2020. Hà Nội: Cục thương mại điện tử và kinh tế số

[35] J. C. Nunnally và I. Bernstein. (1994), The assessment of reliability. Psychometric theory, Vol. 3, No. (1), 248-292.

[36] J. F. Hair, R. E. Anderson, B. J. Babin, và W. C. Black, Multivariate data analysis: A global perspective. Upper Saddle River, NJ: Pearson, 2010.

[37] R. E. Anderson và S. S. Srinivasan. (2003), E-satisfaction and e-loyalty: A contingency framework. Psychology and Marketing, Vol. 20, No. (2), 123-138. doi:10.1002/mar.10063

[38] D. Gefen. (2002), Customer Loyalty in E-Commerce. Journal of the Association for Information Systems, Vol. 3, No. (1), 27-53. doi:10.17705/1jais.00022

[39] V. M. Sharma và A. Klein. (2020), Consumer perceived value, involvement, trust, susceptibility to interpersonal influence, and intention to participate in online group buying. Journal of Retailing and Consumer Services, Vol. 52, No., 101946.

[40] J. P. Trivedi. (2018), Measuring the effect of consumer ethnocentrism and consumer beliefs for herbal products on brand loyalty: a study of Indian FMCG sector. International Journal of Indian Culture and Business Management, Vol. 16, No. (3), 323-338.

[41] T. Albayrak, S. Karasakal, Ö. Kocabulut, và A. Dursun. (2019), Customer Loyalty Towards Travel Agency Websites: The Role of Trust and Hedonic Value. Journal of Quality Assurance in Hospitality \& Tourism, Vol. 21, No. (1), 50-77. doi:10.1080/1528008x.2019.1619497

[42] B. T. Khoa. (2020), The Antecedents of Relationship Marketing and Customer Loyalty: A Case of the Designed Fashion Product. Journal of Asian Finance, Economics and Business, Vol. 7, No. (2), 195-204. doi:10.13106/jafeb.2020.vol7.no2.195

[43] D. Sirdeshmukh, J. Singh, và B. Sabol. (2018), Consumer Trust, Value, and Loyalty in Relational Exchanges. Journal of Marketing, Vol. 66, No. (1), 15-37. doi:10.1509/jmkg.66.1.15.18449

[44] C. Devece, S. Garcia-Agreda, và B. Ribeiro-Navarrete. (2015), The Value of Trust for Travel Agencies in Achieving Customers' Attitudinal Loyalty. Journal of Promotion Management, Vol. 21, No. (4), 516-529. doi:10.1080/10496491.2015.1051409

[45] C. J. Lee. (2011), Understanding bank service quality in customers' terms: an exploratory analysis of top-ofmind definition. International Journal of Business and Social Science, Vol. 2, No. (21).

[46] G. Nadarajah và S. S. Ramalu. (2018), Effects Of Service Quality, Perceived Value And Trust On Destination Loyalty And Intention To Revisit Malaysian Festivals Among International Tourists. International Journal of Recent Advances in Multidisciplinary Research, Vol. 5, No. (01), 3357-3362.

[47] J. L. Tam. (2012), Linking perceived service quality to relational outcomes in a Chinese context. Journal of International Consumer Marketing, Vol. 24, No. (1-2), 7-23.

[48] L. Marakanon và V. Panjakajornsak. (2017), Perceived quality, perceived risk and customer trust affecting customer loyalty of environmentally friendly electronics products. Kasetsart Journal of Social Sciences, Vol. 38, No. (1), 24-30.

[49] H. Huy Tuu, S. Ottar Olsen, và P. Thi Thuy Linh. (2011), The moderator effects of perceived risk, objective knowledge and certainty in the satisfaction-loyalty relationship. Journal of Consumer Marketing, Vol. 28, No. (5), 363-375.

Ngày nhận bài: 29/04/2021 Ngày chấp nhận đăng: 20/07/2021 


\section{Phụ lục 1. Thang đo sử dụng trong nghiên cứu}

\section{A. TÍNH VI CHỦNG (MCE)}

MCE1. Người Việt Nam nên mua hoặc sư dụng các sản phẩm Việt Nam trên các thị truờng diện tử truớc tiên.

MCE2. Không nên mua các sản phẩm của nước ngoài khi đã có các sản phẩm thay thế của Việt Nam trên thị truờng điện tủ.

MCE3. Mua các sản phẩm của nuớc ngoài trên thị truờng điện tủ có thể khiến người Việt Nam mất việc làm.

MCE4. Chỉ nên nhập khẩu các sản phẩm chura có ở Việt Nam trên thị truờng điện tử.

MCE5. Người Việt Nam thì chi nên mua các sản phẩm Việt Nam trên thị trường điện tử.

MCE6. Thích ủng hộ các sản phẩm Việt Nam trên thị trường điện tử hơn, thậm chí nên trả nhiều tiền hơn cho sản phẩm Việt Nam trên các sàn thuoong mại điện tử.

MCE7. Mua các sản phẩm có nguồn gốc nước ngoài trên thị truờng điện tủ có thể làm giảm ý thức về trách nhiệm đối với xã hội.

\section{NIỂM TIN (MOT)}

MOT1. Các nhà bán hàng nội địa trên thị trương điện tử cung cấp đầy đủ thông tin về sản phẩm.

MOT2. Các nhà bán hàng nội địa trên thị truờng điện tư quan tâm đển khách hàng.

MOT3. Nhận xét của nhóm khách hàng đã mua sản phẩm Việt Nam trên thị trường điện tử đáng tin.

MOT4. Hàng hóa Việt Nam trên thị truờng điện tử sẽ không làm tôi thất vọng.

MOT5. Các sản phẩm Việt Nam trên thị trương điện tử sẽ giống thông tin trục tuyến được cung cấp.

\section{RỦI RO CAM NHÂA (MPK)}

MPK1. Hàng hóa trên thị truờng điện tử có thể không đúng chất lương nếu Covid-19 xảy ra ở nước sản xuất.

MPK2. Tôi có thể không nhận được hàng hóa tù nước ngoài khi mua trên thị trường điện tử nếu Covid-19 xảy ra.

MPK3. Hàng hóa mua tù các nhà bán hàng nuớc ngoài có thể bị giao chậm trong bối cảnh Covid-19.

\section{CHÁT LUOO'NG DICH VU (MSQ)}

MSQ1. Các thông tin trên thị truờng điện tử được cập nhật thường xuyên mặc dù Covid-19 đang diễn ra.

$M S Q 2$. Gian hàng trên thị truờng điện tử được tải về máy tính rất nhanh chóng.

MSQ3. Có thể dễ dàng tìm thấy hàng hóa nội địa trên thị truờng điện tư (dễ diều huớng) khi tham gia mua sắm.

MSQ4. Thông tin về các tính năng của sản phẩm Việt Nam được cung cấp đầy đủ trên thị truờng điện tủ.

MSQ5. Khiếu nại sẽ được giải quyết nhanh chóng và hiệu quả trên thị truờng điện tử.

\section{LÒNG TRUNG THÀNH KHÁCH HÀNG (MCL)}

MCL1. Sở thích đối với các sản phẩm Việt Nam trên thị trương điện tử không thay đổi.

MCL2. Sẽ khó thay đổi niềm tin của tôi về hàng Việt Nam trên thị trường điện tứ.

MCL3. Ngay cả khi bạn bè thân thiết giới thiệu sản phẩm nước ngoài, sở thích đối với hàng Việt Nam trên thị trường điện tử vẫn không thay đổi.

MCL4. Sẽ mua hàng Việt Nam trên thị truờng điện tử vào lần kế tiếp nếu cần sản phẩm.

MCL5. Dụ định tiếp tục mua hoặc sử dụng các sản phẩm do Việt Nam sản xuất trên thị truờng điện tử. 